\title{
Remisyonda olan romatoid artritli hastada tedavi kararı
}

\section{Treatment decision in patient with rheumatoid arthritis in remission}

\author{
Ayten Yazıcı
}

Kocaeli Üniversitesi Tıp Fakültesi, İç Hastalıkları Anabilim Dalı Romatoloji Bilim Dalı, İzmir, Kocaeli, Türkiye

\section{Öz}

Romatoid artrit (RA) erişkinde en sık görülen inflamatuar artrit olup, tedavisinde remisyon veya düşük hastalık aktivitesi hedeflenmektedir. Bu nedenle öncelikle RA'da kalıcı remisyon tanımının ve süresinin kesin olarak belirlenmesi gerekmektedir. Mevcut önerilere göre en az altı aydır remisyonda olan ve sabit dozda hastalık modifiye edici ilaç (DMARD) kullanan hastalarda doz azaltılması önerilmektedir. Özellikle anti-siklik sitrüline peptid sonucu negatif, inflamatuar belirteçleri normal olan ve ultrasonografide aktif inflamasyonu olmayan hastalarda steroid kesildikten sonra biyolojik DMARD dozu veya sıklığının azaltılması, sonrasında konvansiyonel DMARD ile kombine kullanan ve halen remisyonda olanlarda biyolojik DMARD'ın kesilmesi relaps açısından daha güvenli görünmektedir. Tek başına konvansiyonel DMARD kullananlarda ise sadece doz azaltılması önerilmektedir.

Anahtar Sözcükler: Romatoid artrit, remisyon, DMARD, relaps.

\begin{abstract}
Rheumatoid arthritis (RA) is the most common inflammatory disease in adults, and remission or low disease activity is targeted for treatment of RA. Therefore, the definition and duration of sustained remission for RA should be determined precisely. According to current recommendations, dose reduction is recommended in patients who use stable dose disease modifying antirheumatic drugs (DMARD) and have been in remission for at least 6 months. Tapering of biologic DMARD (dose or frequency) after steroid discontinuation may be considered, especially in patients who had negative anti cyclic citrullinated peptide, normal inflammatory markers and no active signal in ultrasonography. In persistent remission, discontinuation of biologic DMARD may be considered if treatment combined with a conventional DMARD. Only tapering is recommended for patients who use conventional DMARD as monotherapy.
\end{abstract}

Keywords: Rheumatoid arthritis, remission, DMARD, relapse.

Romatoid artrit (RA) erişkinde en sık görülen inflamatuar artrittir ve son 30 yıl içerisinde tedavisi ile ilgili gelişmeler sayesinde günümüzde RA için tedavi hedefi olarak düşük hastalık aktivitesinden (DHA) hatta remisyondan bahsedilir olmuştur. Özellikle erken dönemde tanı ve tedavi, hedefe yönelik yaklaşımlar ve sıkı kontrol, konvansiyonel hastalık modifiye edici ilaçların (kDMARD) yanı sıra biyolojik DMARD'ların (bDMARD) da kullanımı ile RA'da remisyon, ulaşılabilir bir hedef haline gelmiştir (14). Tüm bu gelişmelerin sonucunda son 10 yıldaki veritabanlarında bildirilen remisyon oranlarının iki kat arttığı görülmüştür (\%40-50 civarında) (4).

RA'da remisyonu değerlendirmek için çeşitli kompozit indeksler, ölçütler kullanılmaktadır (Tablo-1) (5). Bu ölçütlerden biri olan Amerikan romatoloji cemiyeti (ACR) - Avrupa romatoloji cemiyeti (EULAR) indeksine göre hastanın remisyonda kabul edilebilmesi için şiş eklem sayısı, hassas eklem sayısı, hasta global değerlendirme ve c-reaktif protein (CRP)'nin hiçbirinin 1'i geçmemesi (Boolean remisyon) gerekmektedir. 
Tablo-1. Romatoid artritte remisyonu tanımlamak için kullanılan ölçütler (5).

\begin{tabular}{|c|c|c|}
\hline Ölçütler & Remisyon & Düşük Hastalık Aktivitesi \\
\hline Hastalık Aktivite Skoru (DAS) 28 & $<2,6$ & $2,6-3,2$ \\
\hline \multicolumn{3}{|l|}{ Ağrılı eklem sayısı } \\
\hline \multicolumn{3}{|l|}{ Şiş eklem sayısı } \\
\hline \multicolumn{3}{|l|}{ Global sağlık } \\
\hline \multicolumn{3}{|l|}{ CRP veya ESH } \\
\hline Basitleştirilmiş Hastalık Aktivite İndeksi (SDAI) & $\leq 3,3$ & $>3,3-11$ \\
\hline \multicolumn{3}{|l|}{ Ağrılı eklem sayısı } \\
\hline \multicolumn{3}{|l|}{ Şiş eklem sayısı } \\
\hline \multicolumn{3}{|l|}{ Hasta global değerlendirme } \\
\hline \multicolumn{3}{|l|}{ Doktor global değerlendirme } \\
\hline \multicolumn{3}{|l|}{$\mathrm{CRP}$} \\
\hline Klinik Hastalık Aktivite Indexi (CDAI) & $\leq 2,8$ & $>2,8-10$ \\
\hline \multicolumn{3}{|l|}{ Ağrılı eklem sayısı } \\
\hline \multicolumn{3}{|l|}{ Şiş eklem sayısı } \\
\hline \multicolumn{3}{|l|}{ Hasta global değerlendirme } \\
\hline \multicolumn{3}{|l|}{ Doktor global değerlendirme } \\
\hline ACR-EULAR Remisyon & $\mathrm{SDAl} \leq 3,3$ & \\
\hline İndeksler: SDAI, CDAI & $\mathrm{CDAI} \leq 2,8$ & \\
\hline \multicolumn{3}{|l|}{ Boolean: Ağrılı eklem sayısı (28) } \\
\hline Şiş eklem sayısı (28) & Boolean her biri $\leq 1$ & \\
\hline \multicolumn{3}{|l|}{ Hasta global değerlendirme } \\
\hline CRP & & \\
\hline
\end{tabular}

CRP: c-reaktif protein, ESH: eritrosit sedimentasyon hızı

En sık kullanılan ve 28 eklemin değerlendirildiği hastalık aktivite skorunda (DAS28) her bir değerlendirme kriterinin farklı ağırlığa sahip olduğu bir formül kullanılmaktadır. Mesela hassas eklem sayısı bu formülde şiş eklem sayısından iki kat daha fazla değere sahiptir. Ayrıca akut fazların da DAS28'de etkisi fazla; bu nedenle interlökin-6 (IL-6) veya janus kinaz (JAK) inhibitörleri gibi akut fazlara direkt etkili bir ilaç alanlarda hasta remisyonda olmasa bile değerlerin düşük olabileceği unutulmamalıdır. Çalışmalara bakıldığında DAS28 ile bildirilen remisyon oranlarının ACR-EULAR'a göre daha yüksek olduğu (yaklaşık iki kat) görülmektedir (6). Fransa'dan yapılan bir çalışmada hasta (\%47) ve doktorun (\%53) değerlendirmesine göre hastaların yaklaşık yarısı remisyonda olmasına karşın bu oran DAS28'e göre yaklaşık \%62, klinik hastalık aktivite indeksine (CDAl) göre \%36, basitleştirilmiş hastalık aktivite indeksine (SDAI) göre \%40 ve ACR-EULAR'a göre \%32 olarak bildirilmiştir (7). DAS28'e göre remisyonda kabul edilen hastaların sıklıkla gerçek remisyondan ziyade minimal hastalık aktivitesine sahip olduğu ultrasonografi (USG) ve manyetik rezonans (MR) görüntülemelerinde sinovite ait bulguların varlığı ile gösterilmiştir. Pek çok çalışmada DAS28'e göre remisyonda kabul edilip bDMARD'ı azaltılan fakat USG'de sinoviti olanlarda olmayanlara göre daha yüksek relaps riski olduğunu göstermiştir (4). Ayrıca DAS28'e göre remisyonda kabul edilip ilaçları kesilen hastalarda alevlenme oranlarının EULAR-ACR indeksine göre remisyonda kabul edilenlerden daha yüksek olduğu da görülmüştür (6). Bu nedenle remisyondan bahsederken hangi ölçeğin kullanıldığı ve remisyon tanımının geçerliliği önemlidir. Remisyon kabul edilen hastalarda alttaki subklinik hastalık aktivitesini ölçmek ve alevlenme riskini gösterebilmek için görüntüleme ve serum belirteçlerine yönelik çalışmalar yapılmaktadır. Remisyon için klinik remisyonun yeterli olmadığını bunun yanında görüntüleme, serolojik ve immünolojik olarak da remisyonun hedeflenmesi gerektiğini belirten yayınlar mevcuttur (4). 
Remisyonun tanımının yanında süresi de ilacı kesmek veya azaltmak için önemli bir faktördür. Remisyondaki bir hasta tedaviye devam etse bile bir süre sonra remisyondan çıkabilmektedir. Bu nedenle remisyonun stabil ve sürdürülebilir olması gerekmektedir. Çalışmalarda kalıcı remisyon tanımlanırken birkaç aydan bir yıla kadar farklı zaman dilimlerinden bahsedilmektedir. Genel olarak en az altı ay süre ile ve en az üç vizitte (üç ayda bir hastanın değerlendirildiği varsayılarak) dökümente edilmiş remisyon kalıcı remisyon olarak kabul edilmekte ve bu sağlandığı takdirde ilaç değişikliği yapılabileceği önerilmektedir $(4,8)$. Yilmaz ve ark.'nın son dönemde yaptıkları bir çalışmada altıncı aydaki değerlerden ziyade 12. aydaki değerlerin kalıcı remisyon için daha belirleyici olduğu belirtilmiştir (9). Nitekim Asya-Pasifik romatoloji cemiyetinin (APLAR) önerilerinde de 12 aydan fazla remisyon olması durumunda ilaç değişikliğine gidilmesi önerilmektedir (10).

EULAR 2016 RA tedavi önerilerinde kalıcı remisyona ulaşılması halinde öncelikle glukokortikoidlerin (GK) azaltılarak kesilmesi önerilmektedir. Sonrasında sabit dozda DMARD kullanırken remisyon devam ediyorsa biyolojik tedavinin azaltılabileceği, azaltmanın da doz azaltma veya aralık açma şeklinde yapılabileceği belirtilmektedir. Remisyona girmiş hastalarda, kDMARD ile kombine kullanilıyorsa bDMARD'ların tedricen azaltıldıktan sonra kesilebileceği belirtilirken, tek başına kullananlarda hastaların çoğunda relaps görülmesi nedeni ile bDMARD'ın tamamen kesilmesi önerilmemektedir. Relaps sonrası hastaya aynı tedavi başlandığında hastaların yaklaşık \%80'inde iyi yanıt alınsa da bazı hastalarda yanıtsızlık gözlendiği bildirilmiştir. Uzun süreli kalıcı remisyon durumunda sadece kDMARD kullanan hastalar için doz azaltması önerilse de bu ilaçların tamamen kesilmesi pek önerilmemektedir (2). Benzer şekilde ACR 2015 önerilerinde de remisyonda olan hastalarda doz azaltılması önerilmekte, fakat tüm tedavilerin kesilmesi uygun görülmemektedir (3). Benzer önerileri sunan APLAR diğerlerinden farklı olarak 12 aydan uzun süreli remisyon sonrası tedavinin azaltılmasını önermektedir $(10,11)$. Türkiye romatoloji derneğinin (TRD) yukarda bahsedilen önerilerden de yola çıkarak hazırladığı kılavuzda benzer önerilerin paylaşıldığı görülmektedir. Ek olarak bDMARD'ların, ancak bu ilaçların uygulama sıklıklarının üç katına kadar süre uzatılabildiği takdirde kesilebileceği vurgulanmıştır (12).

DMARD'ların azaltılması veya kesilmesi sonrası hastalardaki remisyonda kalma veya relaps sıklıklarının incelendiği çalışmalar bu konuda yol gösterici olacaktır. Sadece kDMARD kullanan ve uzun süreli remisyonda olan RA hastalarında yapılan çalışmalarda ilaçlar kesildikten 3-5 ay sonra hastaların yaklaşık yarısında relaps olduğu görülmektedir (13-15). 7 yıllık takip sonrasında ise ilaçsız remisyon oranlarının \%15'e kadar düştüğü ve bu oranın yerleşik RA'da daha da düşük olduğu bildirilmektedir $(8,14)$. Buna benzer çalışmalarda sadece çok az sayıda hastada ilaçsız kalıcı remisyon sağlanabildiği gözlendiği için hastaların çoğu için ilaçların tamamen kesilmesi, yani kDMARD'ların kesilmesi önerilmemektedir $(2,3,10,11)$.

Biyolojik tedavilerle ilgili verilere bakıldığında doz azaltıldığında kalıcı remisyon oranlarının \%21-88, biyolojik ilaçlar kesildiğinde ise \%13-89 arasında değiştiği görülmektedir. Bu çalışmaların hepsinde kullanılan değerlendirme ölçütünün DAS28 olduğu ve yüksek oran bildiren çalışmaların çoğunda remisyondan ziyade DHA'nin baz alındığı unutulmamalıdır (4). Yapılan çalışmalarda erken RA (\%30-79) hastalarında yerleşik RA'lı (\%13-48) hastalara göre iki kat daha fazla kalıcı remisyon oranları bildirilmektedir (16). HONOR çalışmasında "derin remisyon"da (DAS28 $\leq 1.98$ ) olan hastalarda bir yılın sonunda kalıcı remisyon oranlarının hafif remisyonda (DAS28: 1.98-2.6) olan hastalara göre çok daha yüksek, yani relapsın daha az olduğu görülmüştür (\%68 vs \%25; $p<0,001)$. Bu nedenle remisyon ölçütü olarak DAS28 kullanılacak ise remisyondan ziyade "derin remisyon"un ilaç değişikliği için baz alınması önerilmektedir (17).

bDMARD'lar için doz azaltılması veya ilaç kesilmesi sonrası relaps sıklığı da bu konuda önemli fikirler vermektedir. RETRO çalışması bu açıdan iyi bir çalışma olup 11 merkezden toplam 101 hastanın katıldığı bu çalışmada 12. ayın sonunda ilaç değişikliği yapılanların \%34'ünde relaps görüldüğü, bDMARD dozu azaltılan hastalarda bu oranın \%39'a, ilacı kesilenlerde ise \%52'ye çıktığı bildirilmiştir (18). On altı randomize kontrollü çalışmanın dâhil edildiği 1264 hastalık bir meta-analizde ise anti-TNF ilacının kesilmesi sonrası relaps oranı \%47 olarak bildirilmiştir (19). Ayrıca başka bir meta-analizde biyolojik ilacın kesilmesi (RR: 1,97; \%95 Cl: 1,43-2,73) veya dozunun azaltılmasının (RR:1,23; \%95 Cl: 1,06- 
1,42) relaps için bir risk faktörü olduğu vurgulanmıştır (20). Relaps sonrası biyolojik tedaviye tekrar başlandığında tedavi yanıtı \%7484 arasında bildirilmekte (21) ve anti sitrüline protein antikor (ACPA) pozitifliğinin relaps için iyi bir prediktör olduğu belirtilmektedir $(4,18,22)$.

Biyolojik veya hedefe yönelik tedavilerde ilaç dozunu azaltmaya veya tamamen kesebilmeye yönelik prediktörlerin varlığı tedavi değişikliğinde yol gösterici olabilir. Bu amaçla toplam 5724 hastayı içeren 34 çalışmalık bir derlemede özellikle DHA'nin (13 çalışma), iyi fiziksel fonksiyonun ( 6 çalışma), negatif veya düşük titre romatoid faktör (RF) (5 çalışma) veya ACPA'nın (3 çalışma) iyi birer prediktör olduğu belirtilmektedir. Ayrıca CRP (3 çalışma) veya eritrosit sedimentasyon hızı (ESH)'nin (3 çalışma), kısa hastalık süresi ( 3 çalışma) ve
USG'de düşük sinyalin ( 3 çalışma) görülmesi de önemli faktörler arasında sayılmaktadır (23).

\section{Sonuç}

Remisyonda olan RA'lı hastalarda öncelikle kalıcı remisyon için kesin bir tanım ve sürenin belirlenmesi gerekmektedir. Şimdilik eldeki veriler ve önerilere göre en az altı aydır remisyonda olduğu bilinen ve sabit dozda DMARD kullanan hastalarda doz azaltılması önerilmektedir. Özellikle anti-CCP'si negatif olan, inflamatuar belirteçleri normal olan ve USG'de aktif inflamasyonu olmayan hastalarda steroid kesildikten sonra remisyonun devamı halinde bDMARD dozu veya sıklığının azaltılması güvenli gözükmektedir. kDMARD ile kombine kullananlarda bDMARD kesilmesi düşünülebilir. Tek başına kDMARD kullananlarda ise sadece doz azaltılması önerilmekte tüm ilaçların kesilmesi önerilmemektedir.

\section{Kaynaklar}

1. Gerd RB, Pope JE. Novel treatment strategies in rheumatoid arthritis. Lancet 2017; 389: 2338-48.

2. Smolen JS, Landewe R, Bijlsma J, et al. EULAR recommendations fort he management of rheumatoid arthritis with synthetic and biological disease-modifying antirheumatic drugs: 2016 update. Ann Rheum Dis 2016; 76: 960-77.

3. Singh JA, Saag KG, Bridges SL Jr, et al. 2015 American College of Rheumatology guideline for the treatment of rheumatoid arthritis. Arthritis Rheumatol 2016; 68: 1-26.

4. Schett G, Emery P, Tanaka Y, et al. Tapering biologic and conventional DMARD therapy in rheumatoid arthritis: current evidence and future directions. Ann Rheum Dis. 2016; 75 (8): 1428-37.

5. Smolen SF, Aletaha D, McLnnes IB. Rheumatoid arthritis. Lancet 2016; 388: 2023-38.

6. Aletaha D, Smolen JS. Remission in rheumatoid arthritis: missing objectives by using inadequate DAS28 targets. Nat Rev Rheumatol 2019; doi: 10.1038/s41584-019-0279-6. (Equb ahead of print)

7. Dubost JJ, Pereira B, Fan A, Soubrier M. Rate of remission among rheumatoid arthritis patients being treated by rheumatologist in routine practice. Joint Bone Spine 2019; doi: 10.1016j/jbspin.2019.03.006. (Equb ahead of print)

8. Ajeganova S, Huizinga T. Sustained remission in rheumatoid arthritis: latest evidence and clinical considerations. Ther Adv Musculoskel Dis 2017; 9: 249-62.

9. Yilmaz-Oner S, Gazel U, Can M, Atagunduz P, Direskeneli H, Inanc N. Predictors and the optimal duration of sustained remission in rheumatoid arthritis. Clin Rheumatol 2019; doi: 10.1007/s10067-019-04654-7. (Equb ahead of print)

10. Lau, CS, Chia F, Dans L, et al. 2018 update of the APLAR recommendations for treatment of rheumatoid arthritis. Int J of Rheum Dis 2019; 22: 357-75.

11. Lau CS, Chia F, Harrison A, et al. APLAR rheumatoid arthritis treatment recommendations. Int $\mathrm{J}$ of Rheum Dis 2015; 18: 685-713.

12. Cefle A, Keser G, Terzioğlu E ve ark. Türkiye Romatoloji Derneği romatoid artrit ulusal tedavi önerileri. Ulus Romatol Derg 2018; 10: 81-4.

13. Baker KF, Skelton AJ, Lendrem DW, et al. Predicting drug-free remission in rheumatoid arthritis: A prospective interventional cohort study. J Autoimmun 2019; doi: 10.1016/j.jaut.2019.06.009. (Equb ahead of print)

14. Van den Broke M, Lems WF, Allaart CF. BeSt practice: the success of early-targeted treatment in rheumatoid arthritis. Clin Exp Rheumatol 2012; 30: S35-8. 
15. Sanmarti R, Veale DJ, Martin-Mola E, et al. Reducing or maintaining the dose of subcutaneous tocilizumab in patients with rheumatoid arthritis in clinical remission: a randomized, open-label trial. Arthritis Rheumatol. 2019; doi: 10.1002/art.40905. (Equb ahead of print)

16. Tanaka Y. Stopping tumour necrosis factor-targeted biological DMARDs in rheumatoid arthritis. Rheumatology (Oxford) 2016;55(suppl 2):ii15-ii22.

17. Tanaka $Y$, Hirata $S$, Kubo $S$, et al. Discontinuation of adalimumab after achieving remission in patients with established rheumatoid arthritis: 1-year outcome of the HONOR study. Ann Rheum Dis 2015; 74: 389-95.

18. Haschka J, Englbrecht M, Hueber AJ, et al. Relaps rates in patients with rheumatoid arthritis in stable remission tapering or stopping antirheumatic therapy: interim results from the prospective randomised controlled RETRO study. Ann Rheum Dis 2016; 75: 45-51.

19. Mangoni AA, Okaily FA, Almoallim H, Rashidi SA, Mohammed RHA, Barbary A. Relapse rates after elective discontinuation of anti-TNF therapy in rheumatoid arthritis: a meta-analysis and review of literature. BMC Rheumatol 2019; doi: 10.1186/s41927-019-0058-7. (Equb ahead of print)

20. Henaux S, Ruyssen-Witrand A, Cantagrel A, et al. Risk of losing remission, low disease activity or radiographic progression in case of BDMARD discontinuation or tapering in rheumatoid arthritis: systemic analysis of the literature and meta-analysis. Ann Rheum Dis 2018; 77: 515-22.

21. Tanaka $Y$, Hirata $S$. Is it possible to withdraw biologics from therapy in rheumatoid arthritis? Clin Ther 2013; 35: 2028-35.

22. Tanaka $Y$, Hirata $S$. Intensive intervention can lead to a treatment holiday from biological DMARDs in patients with rheumatoid arthritis. Drugs 2014; 74 (18): 2129-39.

23. Schlager L, Loiskandl M, Alehata D, Radner D. Predictors of successful discontinuation of biologic and targeted synthetic DMARDs in patients with rheumatoid arthritis in remission or low disease activity: a systematic literature review. Rheumatlogy (Oxford) 2019; doi: 10.1093/rheumatology/kez276. (Equb ahead of print). 